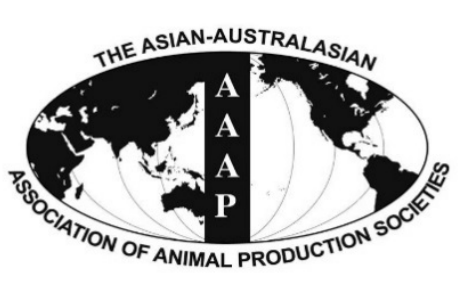

Open Access

Asian Australas. J. Anim. Sci.

Vol. 29, No. 9 : 1331-1337 September 2016

http://dx.doi.org/10.5713/ajas.16.0329

www.ajas.info

pISSN 1011-2367 elSSN 1976-5517

\title{
Comparison of Muscle Fiber and Meat Quality Characteristics in Different Japanese Quail Lines
}

\author{
Y. M. Choi ${ }^{1,2}$, S. Hwang ${ }^{2,3}$, and K. Lee ${ }^{2, *}$ \\ ${ }^{1}$ Department of Animal Sciences, Kyungpook National University, Sangju 37224, Korea
}

\begin{abstract}
The aim of this study was to compare the growth performance, fiber characteristics of the pectoralis major muscle, and meat quality characteristics in the heavy weight (HW) and random bred control (RBC) quail lines and genders. The HW male exhibited more than two times greater body $(245.7$ vs $96.1 \mathrm{~g}, \mathrm{p}<0.05)$ and pectoralis major muscle (PMW; $37.1 \mathrm{vs} 11.1 \mathrm{~g}, \mathrm{p}<0.05)$ weights compared to the RBC female. This growth performance in the HW line was associated with a greater muscle fiber area (1,502 vs 663.0 $\left.\mu \mathrm{m}^{2}, \mathrm{p}<0.001\right)$ compared to the RBC line. Greater muscle mass of the HW male was accompanied by a higher percentage of type IIB fiber compared to the HW female $(64.0 \%$ vs $51.0 \%$, $<<0.05)$. However, muscle fiber hyperplasia (increase in fiber number) has had a somewhat limited effect on PMW between the two lines. On the other hand, the HW line harboring a higher proportion of type IIB fiber showed rapid $\mathrm{pH}$ decline at the early postmortem period (6.23 vs $6.41, \mathrm{p}<0.05)$ and lighter meat surface $(53.5$ vs 47.3 , $\mathrm{p}<0.05)$ compared to the RBC line harboring a lower proportion of type IIB fiber. There were no significant differences observed in the measurement of water-holding capacity including drip loss $(2.74 \%$ vs $3.07 \%, \mathrm{p}>0.05)$ and cooking loss $(21.9 \%$ vs $20.4 \%$, p $>0.05)$ between the HW and RBC lines. Therefore, the HW quail line developed by selection from the RBC quail, was slightly different in the meat quality characteristics compared to the RBC line, and a marked difference was found in growth performance between the two quail lines. (Key Words: Muscle Fiber Characteristics, Growth Performance, Meat Quality, Heavy Weight Quail)
\end{abstract}

\section{INTRODUCTION}

In the last decade, poultry meat production and consumption have rapidly increased in many countries due to the health image of poultry meat products (Petracci et al., 2009). The quail is used as an animal growth model for the muscle development because of its rapid generation time (Choi et al., 2014a, b), and also is a good source for meat products, especially in the Asian market, even though quail egg is more popular compared to meat (Narinc et al., 2013).

The meat industry attempts to improve genetic selection for efficiency in growth and carcass performance (Lopez et al., 2011), and effects of selection on ultimate muscle mass

\footnotetext{
* Corresponding Author: K. Lee. Tel: +1-614-688-7963, Fax: +1614-292-2929, E-mail: lee.2626@osu.edu

2 Department of Animal Sciences, The Ohio State University, Columbus, OH 43210, USA.

${ }^{3}$ Animal Biotechnology Division, National Institute of Animal Science, RDA, Wanju 55365, Korea.

Submitted Apr. 26, 2016; Revised Jun. 3, 2016; Accepted Jun. 16, 2016
}

have been widely investigated in poultry (Velleman et al., 2003), pig (Rehfeldt et al., 2008), and cattle (Picard et al., 2006). Ultimate muscle mass is significantly determined by the number of muscle fibers formed before birth and the size of those fibers after birth (Picard et al., 2006; Rehfeldt et al., 2008). Thus, an increase in muscle mass obtained by selection is mainly due to changes in both the number (hyperplasia) and area (hypertrophy) of muscle fiber (Fowler et al., 1980; Remignon et al., 1995). In chicken, the fast growing line that has a greater muscle mass tended to exhibit a greater number $(20 \%)$ and size $(90 \%)$ of muscle fibers in the pectoralis major muscle compared to the slow growing line (Remignon et al., 1995). The heavy weight (HW) quail line selected for a higher body weight (BW) at 4 weeks after birth showed more than twice the area of muscle fiber at the pectoralis major muscle compared to the random bred control (RBC) line (Choi et al., 2013).

On the other hand, extensive muscle fiber hypertrophy resulting from selection for rapid muscle growth is related with detrimental effects on stress susceptibility and meat 
quality characteristics in meat animals (Karlsson et al., 1999; Velleman et al., 2003). For example, porcine muscles harboring a larger muscle fiber, especially type IIB fiber (fast-twitch and glycolytic), exhibit a rapid early postmortem glycolytic rate, paler surface, higher drip loss, and tougher meat compared to muscles harboring a smaller muscle fiber, which seems to be associated with the pale, soft, and exudative (PSE) condition (Choi and Kim, 2009). Like the PSE condition in pork, the poultry industry has recently experienced a meat quality problem due to a change in the morphological and metabolic characteristics of muscle fiber resulting from a selection for increased ultimate muscle mass (Velleman et al., 2002). There are many studies investigating how genetic selection influences muscle fiber and meat quality characteristics in chicken and turkey (Fowler et al., 1980; Cherel et al., 1994; Remignon et al., 1995; Velleman et al., 2002; 2003). However, there are only a few studies conducted on meat quality characteristics between the Japanese quail lines, even though there are many reports regarding the effects of genetic selection on ultimate muscle mass and fiber characteristics (Narinc et al., 2013; Choi et al., 2014a; Shin et al., 2015). Therefore, the objective of this study was to compare the characteristics of the pectoralis major muscle, muscle fiber, and meat quality characteristics between the HW and RBC quail lines to better understand the effects of selection for production efficiency of quail.

\section{MATERIALS AND METHODS}

\section{Birds and muscle samples}

Fertile eggs from the RBC and $\mathrm{HW}$ quail lines were obtained from the Ohio Agricultural Research and Development Center of the Ohio State University in Wooster (OH, USA). Eggs were incubated in a hatchery (Type 65Hs, Masalles, Spain). After hatching, quail from each line were reared in temperature controlled cages with free access to food and water. Quail were fed a commercial diet in accordance with the National Research Council (1988). All the experiments were approved by the Institutional Animal Care and Use Committee at the Ohio State University (protocol no. 2013A00000041).

At $42 \mathrm{~d}$ of age, six males and seven females from each line (total 13 quail per each line) were randomly selected from the hatchery and weighed. Chicks were individually euthanized by $\mathrm{CO}_{2}$ inhalation following standard procedures (FASS, 1999). Pectoralis major muscles were exposed, and all right and left muscles were excised and weighed. The percentage of pectoralis major muscle weight (PMW) was calculated as the ratio of PMW to BW. Area of pectoralis major muscle was measured at the diagonal line of a point $1 / 2$ in the pectoralis major muscle (Scheuermann et al., 2004). Muscle samples were immediately taken from the entire right pectoralis major muscles for the analysis of

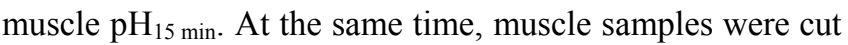
into $0.5 \times 0.5 \times 1.0 \mathrm{~cm}^{3}$ pieces from the superficial region of pectoralis major muscle, then immediately frozen using liquid nitrogen and stored at $-80^{\circ} \mathrm{C}$ for the histochemical analysis. After $24 \mathrm{~h}$ in a $4^{\circ} \mathrm{C}$ cold room, the remaining pectoralis major muscles were used for meat quality measurements.

\section{Histochemical characteristics}

Serial transverse skeletal muscle sections $(10 \mu \mathrm{m})$ were cut in a cryostat (CM1510S, Leica, Wetzlar, Germany) at $-25^{\circ} \mathrm{C}$ and mounted onto glass slides. The myosin ATPase activity of the samples was detected following acid ( $\mathrm{pH}$ 4.6) and alkali $(\mathrm{pH}$ 10.7) pre-incubation (Lind and Kernell, 1991). Muscle fibers were classified as type IIA and IIB fibers using the nomenclature system of Brooke and Kaiser (1970). Type I fibers were not found in the pectoralis major muscle of the RBC and HW quail lines. All stained muscle sections from each sample were examined by an image analysis (Image Pro-Plus, Media Cybernetics, Silver Spring, MD, USA). Approximately 600 fibers were measured per sample. The average area of muscle fibers was determined as the ratio of total area measured divided by total number of fibers, and the area of type IIA and IIB fibers was also measured. Area percentage of each fiber type was calculated as the proportion of total cross sectional area of each fiber type divided by total fiber area measured. Number percentage of each fiber type was calculated as the proportion of total number of each fiber type divided by total fiber numbers measured. Total number of fibers (TFN) was determined by multiplying muscle fiber density by the area of pectoralis major muscle (Scheuermann et al., 2004).

\section{Meat quality measurements}

In order to estimate the postmortem metabolic rate, muscle $\mathrm{pH}$ at $15 \mathrm{~min}\left(\mathrm{pH}_{15} \mathrm{~min}\right)$ and $24 \mathrm{~h}\left(\mathrm{pH}_{24} \mathrm{~h}\right)$ were measured directly inserting a spear-type portable $\mathrm{pH}$ meter (IQ-150 pH meter and PH77-SS probe, IQ Scientific Instruments Inc., San Diego, CA, USA) into the superficial region of the right pectoralis major muscle. At $24 \mathrm{~h}$ postmortem, meat color was measured by a Minolta chromameter (diffuse illumination with $8 \mathrm{~mm}$ diameter measuring area with; CR-300, Minolta Camera Co., Osaka, Japan) after exposing its surface to the air for $30 \mathrm{~min}$ at $4^{\circ} \mathrm{C}$. The average of triplicate measurements was recorded and used. The results were expressed as Commission Internationale de l'Eclairage (CIE, 1978) lightness $\left(L^{*}\right)$, redness $\left(a^{*}\right)$, and yellowness $\left(b^{*}\right)$.

Water holding capacity (WHC) including drip loss and cooking loss was also measured. For measurement of drip loss, samples of approximately $5 \mathrm{~g}$ taken at $24 \mathrm{~h}$ postmortem were trimmed and individually weighed. Each 
sample was then placed and suspended in an inflated plastic bag for $48 \mathrm{~h}$ at $4^{\circ} \mathrm{C}$, ensuring that the sample did not make contact with the bag, after which they were reweighed (Honikel, 1998). Drip loss was calculated as the percentage of weight change (Honikel, 1998). To determine cooking loss, each sample taken from the left pectoralis major muscle was weighed, and then put in a thin-walled polyethylene bag and placed in a water bath $\left(80^{\circ} \mathrm{C}\right)$ until they reached an internal temperature (measured using a thermometer with a hand probe; TES-1300, TES Electrical Electronic Co., Taipei, Taiwan) of $71^{\circ} \mathrm{C}$. Quail samples were then cooled in ice water for $15 \mathrm{~min}$. The cooled samples were taken from the polyethylene bag, blotted dry, and re-weighed (Honikel, 1998). Cooking loss was determined by weighing them before and after cooking loss (Honikel, 1998).

\section{Statistical analysis}

General linear model procedure was performed for associations among the groups using SAS software (SAS Institute, 2009). Significant differences in values among the groups were detected by the probability difference (PDIFF), and the mean values were separated at the level of $5 \%$. Results were presented as least squares means together with the standard errors.

\section{RESULTS}

\section{Body and pectoralis major muscle characteristics}

The results for the BW and pectoralis major muscle characteristics of the HW and RBC Japanese quail lines are presented in Table 1. BW was approximately 2.3 times heavier in the HW quail line selected for a higher body weight compared to the RBC quail line (240.0 vs $102.2 \mathrm{~g}$, $\mathrm{p}<0.001$ ). The BW of the HW male was at least 2.5 times heavier compared to the RBC female (245.7 vs $96.1 \mathrm{~g}$, $\mathrm{p}<0.05)$. PMW was more than 3 times greater in the $\mathrm{HW}$ line compared to the RBC line (35.4 vs $11.6 \mathrm{~g}, \mathrm{p}<0.001)$. The proportion of PMW relative to body weight was higher in the HW line compared to the RBC line (14.6\% vs $11.4 \%$, $\mathrm{p}<0.001)$. Moreover, the area of pectoralis major muscle was also greater in the HW line compared to the RBC quail line (605.0 vs $\left.298.5 \mathrm{~mm}^{2}, \mathrm{p}<0.001\right)$. However, there were no significant differences in the area of pectoralis major muscle (319.7 vs $\left.277.4 \mathrm{~mm}^{2}, \mathrm{p}>0.05\right)$ and percentage of PMW (11.4\% vs $11.5 \%, p>0.05)$ between the RBC male and RBC female.

\section{Muscle fiber characteristics}

There are marked differences in muscle fiber characteristics between the HW and RBC quail lines (Table $2)$. The HW line exhibited a greater mean fiber area $(1,502$ vs $\left.663.0 \mu \mathrm{m}^{2}, \mathrm{p}<0.001\right)$ and type IIA fiber area (866.4 vs $\left.428.8 \mu \mathrm{m}^{2}, \mathrm{p}<0.001\right)$ compared to the $\mathrm{RBC}$ quail line. Especially, mean fiber area was approximately 2.5 times greater in the HW male compared to the RBC female $(1,570$ vs $\left.622.1 \mu \mathrm{m}^{2}, \mathrm{p}<0.05\right)$. There were no significant differences in type IIB fiber area between the RBC and HW lines $\left(1,593\right.$ vs $\left.1,999 \mu \mathrm{m}^{2}, \mathrm{p}>0.05\right)$. Moreover, TFN was also similar between the RBC and HW lines ( 503.5 vs 482.0 $\times 1,000, p>0.05)$. The HW male showed a lower area percentage of type IIA fiber $(19.4 \%$ vs $47.4 \%$ and $57.3 \%$, $\mathrm{p}<0.05)$ and a higher area percentage of type IIB fiber $(80.6 \%$ vs $52.7 \%$ and $42.7 \%, \mathrm{p}<0.05)$ compared to the $\mathrm{RBC}$ male and female. Within the RBC or HW lines, no significant difference was observed in the area percentage of type IIA and IIB fibers between genders $(\mathrm{p}>0.05)$. Whereas, a lower number percentage of type IIA fiber was observed in the HW male compared to the HW female $(36.0 \%$ vs $49.0 \%, \mathrm{p}<0.05)$, even though there was no significant difference in the number percentage of type IIA fiber between the RBC male and RBC female (78.0\% vs $81.0 \%, p>0.05)$. Similar to the area percentage of type IIB fiber, the HW line had a higher number percentage of type IIB fiber compared to the RBC line $(57.5 \%$ vs $20.5 \%$, $\mathrm{p}>0.001)$.

\section{Meat quality characteristics}

Table 3 shows the meat quality characteristics of pectoralis major muscle on the different quail lines and genders. Samples from the HW male showed significantly lower values of muscle $\mathrm{pH}_{15}$ min compared to samples from

Table 1. Body weight and pectoralis major (PM) muscle characteristics of the different quail lines and sex

\begin{tabular}{|c|c|c|c|c|c|c|c|}
\hline \multirow{2}{*}{$\begin{array}{l}\text { Quail line }(\mathrm{Q}) \\
\text { Sex }(\mathrm{S})\end{array}$} & \multicolumn{2}{|c|}{$\mathrm{RBC}$} & \multicolumn{2}{|c|}{ HW } & \multicolumn{3}{|c|}{ Level of significance } \\
\hline & $\begin{array}{c}\text { Male } \\
(N=6)\end{array}$ & $\begin{array}{l}\text { Female } \\
(N=7)\end{array}$ & $\begin{array}{c}\text { Male } \\
(N=6)\end{array}$ & $\begin{array}{l}\text { Female } \\
(N=7)\end{array}$ & Q & $\mathrm{S}$ & $\mathrm{Q} \times \mathrm{S}$ \\
\hline Body weight (BW, g) & $108.2^{\mathrm{b}}(7.23)^{1}$ & $96.1^{\mathrm{b}}(6.70)$ & $245.7^{\mathrm{a}}(7.23)$ & $234.1^{\mathrm{a}}(6.70)$ & $* * *$ & NS & NS \\
\hline PM muscle weight (PMW, g) & $12.2^{\mathrm{c}}(1.33)$ & $11.1^{\mathrm{c}}(1.23)$ & $37.1^{\mathrm{a}}(1.33)$ & $33.6^{\mathrm{b}}(1.23)$ & $* * *$ & NS & NS \\
\hline PMW/BW (\%) & $11.4^{\mathrm{b}}(0.70)$ & $11.5^{\mathrm{b}}(0.64)$ & $15.2^{\mathrm{a}}(0.70)$ & $14.1^{\mathrm{a}}(0.64)$ & $* * *$ & NS & NS \\
\hline PM muscle area $\left(\mathrm{mm}^{2}\right)$ & $319.7^{\mathrm{b}}(58.1)$ & $277.4^{\mathrm{b}}(67.1)$ & $656.0^{\mathrm{a}}(58.1)$ & $553.9^{\mathrm{a}}(67.1)$ & $* * *$ & NS & NS \\
\hline
\end{tabular}

$\mathrm{RBC}$, random bred control; HW, heavy weight; NS, not significant.

${ }^{1}$ Standard error of least square means.

${ }^{a-c}$ Different superscripts in the same row represent significant differences $(p<0.05)$

$* * * \mathrm{p}<0.001$ 
Table 2. Muscle fiber characteristics of the pectoralis major muscle on the different quail lines and sex

\begin{tabular}{|c|c|c|c|c|c|c|c|}
\hline \multirow{2}{*}{$\begin{array}{l}\text { Quail line (Q) } \\
\text { Sex (S) }\end{array}$} & \multicolumn{2}{|c|}{$\mathrm{RBC}$} & \multicolumn{2}{|c|}{ HW } & \multicolumn{3}{|c|}{ Level of significance } \\
\hline & Male & Female & Male & Female & Q & $\mathrm{S}$ & $\mathrm{Q} \times \mathrm{S}$ \\
\hline \multicolumn{8}{|l|}{ Fiber area $\left(\mu \mathrm{m}^{2}\right)$} \\
\hline Mean & $704.0^{\mathrm{b}}(143.7)^{1}$ & $622.1^{\mathrm{b}}(124.4)$ & $1,570^{\mathrm{a}}(143.7)$ & $1,435^{\mathrm{a}}(124.4)$ & $* * *$ & NS & NS \\
\hline Type IIA fiber & $432.6^{\mathrm{b}}(109.2)$ & $425.1^{\mathrm{b}}(94.6)$ & $872.4^{\mathrm{a}}(109.2)$ & $860.3^{\mathrm{a}}(94.6)$ & $* * *$ & NS & NS \\
\hline Type IIB fiber & $1,679(225.4)$ & $1,506(195.2)$ & $1,995(225.4)$ & $2,006(195.4)$ & NS & NS & NS \\
\hline Total fiber number $(\times 1,000)$ & $493.2(53.2)$ & $513.8(46.1)$ & $439.2(53.2)$ & $523.8(46.1)$ & NS & NS & NS \\
\hline \multicolumn{8}{|l|}{ Fiber area percentage $(\%)$} \\
\hline Type IIA fiber & $47.4^{\mathrm{a}}(4.35)$ & $57.3^{\mathrm{a}}(3.77)$ & $19.4^{\mathrm{b}}(4.35)$ & $29.1^{\mathrm{b}}(3.77)$ & $* * *$ & $*$ & NS \\
\hline Type IIB fiber & $52.7^{\mathrm{b}}(4.35)$ & $42.7^{\mathrm{b}}(3.77)$ & $80.6^{\mathrm{a}}(4.35)$ & $70.9^{\mathrm{a}}(3.77)$ & $* * *$ & $*$ & NS \\
\hline \multicolumn{8}{|l|}{ Fiber number percentage (\%) } \\
\hline Type IIA fiber & $78.0^{\mathrm{a}}(3.90)$ & $81.0^{\mathrm{a}}(3.38)$ & $36.0^{\mathrm{c}}(3.90)$ & $49.0^{\mathrm{b}}(3.38)$ & $* * *$ & $*$ & NS \\
\hline Type IIB fiber & $22.0^{\mathrm{c}}(3.90)$ & $19.0^{\mathrm{c}}(3.38)$ & $64.0^{\mathrm{a}}(3.90)$ & $51.0^{\mathrm{b}}(3.38)$ & $* * *$ & $*$ & NS \\
\hline
\end{tabular}

RBC, random bred control; HW, heavy weight; NS, not significant.

${ }^{1}$ Standard error of least square means.

${ }^{\mathrm{a}-\mathrm{c}}$ Different superscripts in the same row represent significant differences $(\mathrm{p}<0.05)$.

$* \mathrm{p}<0.05 ; * * * \mathrm{p}<0.001$

the RBC male and female ( 6.16 vs 6.40 and $6.41, \mathrm{p}<0.05$ ). However, ultimate muscle $\mathrm{pH}\left(\mathrm{pH}_{24} \mathrm{~h}\right)$ was not different between the HW and RBC lines (5.47 vs $5.53, \mathrm{p}>0.05$ ). The HW line showed a higher lightness compared to the RBC line (53.5 vs 47.3, $\mathrm{p}<0.05$ ), although no significant difference was observed in lightness between the HW female and RBC male (53.0 vs 48.8 , $\mathrm{p}>0.05$ ). Comparing the quail lines, the RBC line exhibited a redder surface than the HW line (5.92 vs 5.44, $\mathrm{p}<0.001)$. In the measurement of WHC, there was no significant difference in drip loss between the HW and RBC lines $(2.74 \%$ vs $3.07 \%$, p $>0.05)$ or between the male and female quail $(2.48 \%$ vs $3.29 \%$, $\mathrm{p}>0.05$ ). Moreover, cooking loss was also not different between the HW and RBC lines $(20.4 \%$ vs $21.9 \%$, p $>0.05)$.

\section{DISCUSSION}

A dramatic postnatal increase in growth performance can be acquired by breeding and genetic selection of food animals (Rehfeldt et al., 2000). In the past, poultry performance has been improved by selection, thus the modern commercial poultries are largely the end result of a long continuous process of domestication, especially the pectoralis muscle (Chiang et al., 2008). The age when meattype chicken reach market weight has been reduced, and broilers also have a greater PMW, which is economically important, as well as, a higher proportion of PMW to the BW (Fanatico et al., 2007). In the current study, the HW quail line exhibited a greater growth performance including BW, PMW, and ratio of PMW compared to the RBC quail line. This difference between the HW and RBC lines can be explained by the characteristics of muscle fiber such as the composition and morphological characteristics of fiber type, since the characteristic of muscle fiber as the major constituent of skeletal muscle is one of the important factors that influence BW and skeletal muscle mass (Picard et al.,

Table 3. Meat quality characteristics of the pectoralis major muscle on the different quail lines and sex

\begin{tabular}{|c|c|c|c|c|c|c|c|}
\hline \multirow{2}{*}{$\begin{array}{l}\text { Quail line (Q) } \\
\text { Sex (S) }\end{array}$} & \multicolumn{2}{|c|}{$\mathrm{RBC}$} & \multicolumn{2}{|c|}{ HW } & \multicolumn{3}{|c|}{ Level of significance } \\
\hline & Male & Female & Male & Female & Q & $\mathrm{S}$ & $\mathrm{Q} \times \mathrm{S}$ \\
\hline \multicolumn{8}{|c|}{ Postmortem glycolytic rate } \\
\hline Muscle $\mathrm{pH}_{15} \min$ & $6.40^{\mathrm{a}}(0.06)^{1}$ & $6.41^{\mathrm{a}}(0.07)$ & $6.16^{\mathrm{b}}(0.06)$ & $6.29^{\mathrm{ab}}(0.07)$ & $*$ & NS & NS \\
\hline Muscle $\mathrm{pH}_{24 \mathrm{~h}}$ & $5.51(0.04)$ & $5.56(0.05)$ & $5.45(0.04)$ & $5.49(0.05)$ & NS & NS & NS \\
\hline \multicolumn{8}{|l|}{ Meat color } \\
\hline Lightness $\left(L^{*}\right)$ & $48.8^{\mathrm{bc}}(1.22)$ & $45.8^{\mathrm{c}}(1.41)$ & $54.1^{\mathrm{a}}(1.22)$ & $53.0^{\mathrm{ab}}(1.41)$ & $* * *$ & NS & NS \\
\hline Redness $\left(a^{*}\right)$ & $5.96^{\mathrm{a}}(0.08)$ & $5.88^{\mathrm{a}}(0.09)$ & $5.42^{\mathrm{b}}(0.08)$ & $5.46^{\mathrm{b}}(0.09)$ & $* * *$ & NS & NS \\
\hline Yellowness $\left(b^{*}\right)$ & $12.9(1.13)$ & $12.7(1.30)$ & $12.3(1.13)$ & $12.6(1.30)$ & NS & NS & NS \\
\hline \multicolumn{8}{|c|}{ Water-holding capacity } \\
\hline Drip loss $(\%)$ & $2.92(0.37)$ & $3.21(0.43)$ & $2.03(0.37)$ & $3.45(0.43)$ & NS & NS & NS \\
\hline Cooking loss (\%) & $19.5(1.19)$ & $21.3(1.27)$ & $21.0(1.19)$ & $22.9(1.27)$ & NS & NS & NS \\
\hline
\end{tabular}

RBC, random bred control; HW, heavy weight; NS, not significant.

${ }^{1}$ Standard error of least square means.

${ }^{a-c}$ Different superscripts in the same row represent significant differences $(p<0.05)$.

$* \mathrm{p}<0.05 ; * * * \mathrm{p}<0.001$ 
2006; Choi and Kim, 2009).

On the other hand, due to a long-term domestication and selection process, the muscling phenotypes have been changed in various food animals resulting in extreme differences in muscle fiber characteristics (Rehfeldt et al., 2000). For example, domestic pigs showed a larger area of muscle fibers and a higher percentage of type IIB fiber compared to wild pigs (Ruusunen and Puolanne, 2004). In broiler-type chickens harboring a greater muscle mass, the pectoralis major muscle is composed of type IIB fiber, and type I and IIA fibers are not found in the superficial region of the pectoralis major muscle (Choi et al., 2013). Crosssectional area of type IIB fiber is generally larger, as the growth rate of type IIB fiber after birth is approximately two times greater compared to type I fiber (Oksbjerg et al., 1994). Hence, the area or proportion of type IIB fiber is positively correlated to $\mathrm{BW}$ and muscle mass in food animals (Choi and Kim, 2009). The results from the current study support this notion. In the present study, the HW line harboring a greater muscle mass exhibited a higher area proportion of type IIB fiber compared to the RBC line (75.8\% vs $47.7 \%, \mathrm{p}<0.001)$. Unlike domestic meat-type chickens, pectoralis major muscle of the HW quail line was composed of type IIA and type IIB fibers, even though proportion of type IIA fiber was smaller compared to the RBC line $(\mathrm{p}<0.001)$. Moreover, muscle fiber hyperplasia (increase in muscle fiber number) had a limited contribution to the increased muscle mass in the HW line compared to the RBC line unlike the other meat-type animals including the chicken and turkey (Remignon et al., 1995; Rehfeldt et al., 2000; Choi and Kim, 2009). Generally, increased muscle fiber number (hyperplasia) and area (hypertrophy) have been reported in growth-selected pigs, cattle, chickens, and turkeys (Remignon et al., 1995; Rehfeldt et al., 2000; Choi and Kim, 2009). Additionally, the HW male exhibited a greater PMW compared to the HW female (37.1 vs $33.6 \mathrm{~g}$, $\mathrm{p}<0.05$ ), although $\mathrm{BW}$ was similar between the HW male and female $(p>0.05)$. This greater muscle mass of the HW male was accompanied by a higher proportion of type IIB fiber compared to the HW female $(64.0 \%$ vs $51.0 \%$, $\mathrm{p}<0.05$ ).

Muscle fiber can be classified into several different types based on their contractile and metabolic characteristics (Pette and Staron, 2001). These characteristics influence the energy metabolism within the skeletal muscle of living animals, as well as, during the postmortem conversion of muscle to meat (Ryu and Kim, 2005). The ATP splitting rate of type IIB fiber is more than three times faster compared to type I fiber suggesting a faster contraction speed, and type IIA fiber exhibits intermediate speed of contraction (Bottinelli et al., 1994). Moreover, type IIB fibers (fast-twitch and glycolytic) contain a higher amount of glycogen which offers a source of anaerobic metabolic fuel, and they also contain lower amounts of lipid and myoglobin compared to the type I (Slow-twitch and oxidative) and IIA (fast-twitch and oxidoglycolytic) fibers (Choi and Kim, 2009). Thus, when the oxygen supply is depleted after exsanguination, muscles harboring a higher proportion of type IIB fiber tend to have a rapid decline of $\mathrm{pH}$ at the early postmortem period compared to muscles harboring a lower proportion of type IIB fiber due to strong glycolytic potential (Choi et al., 2007). Ryu and Kim (2005) suggested that rapid glycolytic rate and poor meat quality in PSE can be explained by an increase in the proportion of type IIB fiber. In this study, the HW quail line harboring a higher percentage of type IIB fiber exhibited lower muscle $\mathrm{pH}$ at the early postmortem period and paler surface color compared to the RBC line harboring a lower percentage of type IIB fiber. Fresh meat color is an important quality trait that consumers consider when making a decision to purchase meat, and redder meat surface is generally preferred (Jeong et al., 2010). Even though the HW quail line showed a higher lightness value (53.5 and 45.0), the average redness value of the HW line was similar (5.44 and 5.47) compared to the other study reported by Remignon et al. (1998). It is generally accepted that the ability of fresh meat to bind water is certainly one of the most important quality characteristics (HuffLonergan and Lonergan, 2005). According to Jeong et al. (2010), a lower WHC of fresh meat was associated with poor tenderness and juiciness after cooking, as well as economic value of meat (Huff-Lonergan and Lonergan, 2005). In this study, no significant differences were observed in the measurements of WHC between the two quail lines or genders.

Taken together, the results from this study suggest that greater BW and PMW of the HW line were caused by muscle fiber hypertrophy rather than fiber hyperplasia, and the difference in PMW between the HW male and HW female was associated with the percentage of type IIB fiber. The HW quail line developed by selection from the RBC quail for over 80 generations were slightly different in the meat quality characteristics compared to the RBC line.

\section{CONFLICT OF INTEREST}

We certify that there is no conflict of interest with any financial organization regarding the material discussed in the manuscript.

\section{ACKNOWLEDGMENTS}

This project was supported by SEEDS: The Ohio Agricultural Research and Development Center (OARDC) 
Research Enhancement Competitive Grants Program no.2013-044 at The Ohio State University, and by the National Research Foundation of Korea and the Agenda Program no. PJ010956.

\section{REFERENCES}

Bottinelli, R., R. Betto, S. Schiaffino, and C. Reggiani. 1994. Unloaded shortening velocity and myosin heavy chain and alkali light chain isoform composition in rat skeletal muscle fibres. J. Physiol. 478:341-349.

Brooke, M. H. and K. K. Kaiser. 1970. Three 'myosin adenosine triphosphatase' systems: the nature of their $\mathrm{pH}$ lability and sulphydryl dependence. J. Histochem. Cytochem. 18:670-672.

Cherel, Y., M. Hurtrel, M. F. Gardahaut, F. Merly, C. MagrasResch, J. Fontaine-Perus, and M. Wyers. 1994. Comparison of postnatal development of anterior latissimus dorsi (ALD) muscle in heavy- and light-weight strains of turkey (Meleagris gallopavo). Growth Dev. Aging 58:157-165.

Chiang, W., A. Booren, and G. Strasburg. 2008. The effect of heat stress on thyroid hormone response and meat quality in turkeys of two genetic lines. Meat Sci. 80:615-622.

Choi, Y. M. and B. C. Kim. 2009. Muscle fiber characteristics, myofibrillar protein isoforms, and meat quality. Livest. Sci. 122:105-118.

Choi, Y. M., S. Shin, M. P. Wick, J. H. Choe, and K. Lee. 2013. Muscle fiber characteristics of pectoralis major muscle as related to muscle mass in different Japanese quail lines. Animal 7:1665-1670.

Choi, Y. M., Y. C. Ryu, and B. C. Kim. 2007. Influence of myosin heavy- and light chain isoforms on early postmortem glycolytic rate and pork quality. Meat Sci. 76:281-288.

Choi, Y. M., Y. Suh, J. Ahn, and K. Lee. 2014a. Muscle hypertrophy in heavy weight Japanese quail line: Delayed muscle maturation and continued muscle growth with prolonged upregulation of myogenic regulatory factors. Poult. Sci. 93:2271-2277.

Choi, Y. M., Y. Suh, S. Shin, and K. Lee. 2014b. Skeletal muscle characterization of Japanese quail line selectively bred for lower body weight as an avian model for delayed muscle growth with hypoplasia. PLoS ONE 9:e95932.

CIE (Commission Internationale de l'Eclairage). 1978. Recommendations on uniform color spaces - color differences equations, psychrometic color terms (Supplement No. 2). CIE Publication No. 15 (E1.3.1), Paris, France.

Fanatico, A. C., P. B. Pillai, J. L. Emmert, and C. M. Owens. 2007. Meat quality of slow-and fast-growing chicken genotypes fed low-nutrient or standard diets and raised indoors or with outdoor access. Poult. Sci. 86:2245-2255.

FASS (The Federation of Animal Science Societies). 1999. Guide for the Care and Use of Agricultural Animals in Agricultural Research and Teaching. 1st rev. edn. Federation of Animal Sciences Societies, Savoy, IL, USA.

Fowler, S. P., D. R. Campion, H. L. Marks, and J. O. Reagan. 1980. An analysis of skeletal muscle response to selection for rapid growth in Japanese quail (Coturnix coturnix japonica). Growth 44:235-252.
Honikel, K. O. 1998. Reference methods for the assessment of physical characteristics of meat. Meat Sci. 49:447-457.

Huff-Lonergan, E. and S. M. Lonergan. 2005. Mechanisms of water-holding capacity of meat: The role of postmortem biochemical and structural changes. Meat Sci. 71:194-204.

Jeong, D. W., Y. M. Choi, S. H. Lee, J. H. Choe, K. C. Hong, H. C. Park, and B. C. Kim. 2010. Correlations of trained panel sensory values of cooked pork with fatty acid composition, muscle fiber type, and pork quality characteristics in Berkshire pigs. Meat Sci. 86:607-615.

Karlsson, A. H., R. E. Klont, and X. Fernandez. 1999. Skeletal muscle fibres as factors for pork quality. Livest. Prod. Sci. 60:255-269.

Lind, A. and D. Kernell. 1991. Myofibrillar ATPase histochemistry of rat skeletal muscles: a "two-dimensional" quantitative approach. J. Histochem. Cytochem. 39:589-597.

Lopez, K. P., M. W. Schilling, and A. Corzo. 2011. Broiler genetic strain and sex effects on meat characteristics. Poult. Sci. 90:1105-1111.

Narinc, D., T. Aksoy, E. Karaman, A. Aygun, M. Z. Firat, and M. K. Uslu. 2013. Japanese quail meat quality: Characteristics, heritabilities, and genetic correlations with some slaughter traits. Poult. Sci. 92:1735-1744.

NRC (National Research Council). 1994. Nutrient Requirements of Poultry. 9th rev. edn. National Academies Press, Washington, DC, USA.

Oksbjerg, N., P. Henckel, T. Rolph, and T. Erlandsen. 1994. Effects of salbutamol, a $\beta_{2}$-adrenergic agonist, on muscles of growing pigs fed different levels of dietary protein. I. Muscle fibre properties and muscle protein accretion. Acta Agric. Scand. A Anim. Sci. 44:12-19.

Petracci, M., M. Bianchi, and C. Cavani. 2009. The European perspective on pale, soft, exudative conditions in poultry. Poult. Sci. 88:1518-1523.

Pette, D. and R. S. Staron. 2001. Transitions of muscle fiber phenotypic profiles. Histochem. Cell Biol. 115:359-372.

Picard, B., C. Jurie, M. P. Duris, and G. Renand. 2006. Consequences of selection for higher growth rate on muscle fibre development in cattle. Livest. Sci. 102:107-120.

Rehfeldt, C., I. Fiedler, G. Dietl, and K. Ender. 2000. Myogenesis and postnatal skeletal muscle cell growth as influenced by selection. Livest. Prod. Sci. 66:177-188.

Rehfeldt, C., M. Henning, and I. Fiedler. 2008. Consequences of pig domestication for skeletal muscle growth and cellularity. Livest. Sci. 116:30-41.

Remignon, H., A. D. Mills, D. Guemene, V. Desrosiers, M. Garreau-Mills, M. Marche, and G. Marche. 1998. Meat quality traits and muscle characteristics in high and low fear lines of Japanese quails (Coturnix japonica) subjected to acute stress. Br. Poult. Sci. 39:372-378.

Remignon, H., M. F. Gardahaut, G. Marche, and F. H. Ricard. 1995. Selection for rapid growth increases the number and the size of muscle fibers without changing their typing in chickens. J. Muscle Res. Cell Motil. 16:95-102.

Ruusunen, M. and E. Puolanne. 2004. Histochemical properties of fibre types in muscles of wild and domestic pigs and the effect of growth rate on muscle fibre properties. Meat Sci. 67:533539. 
Ryu, Y. C. and B. C. Kim. 2005. The relationship between muscle fiber characteristics, postmortem metabolic rate, and meat quality of pig longissimus dorsi muscle. Meat Sci. 71:351-357.

SAS Institute. 2009. SAS User's Guide: Statistics. Version 9.3. SAS Inst. Inc., Cary, NC, USA.

Scheuermann, G. N., S. F. Bilgili, S. Tuzun, and D. R. Mulvaney. 2004. Comparison of chicken genotypes: myofiber number in pectoralis muscle and myostatin ontogeny. Poult. Sci. 83:14041412.
Shin, S., Y. M. Choi, Y. Suh, and K. Lee. 2015. Delta-like 1 homolog (DLK1) inhibits proliferation and myotube formation of avian QM7 myoblasts. Comp. Biochem. Physiol. B. Biochem. Mol. Biol. 179:37-43.

Velleman, S. G., C. S. Coy, J. W. Anderson, R. A. Patterson, and K. E. Nestor. 2003. Effect of selection for growth rate and inheritance on posthatch muscle development in turkeys. Poult. Sci. 82:1365-1372.

Velleman, S. G., C. S. Coy, J. W. Anderson, R. A. Patterson, and K. E. Nestor. 2002. Effect of selection for growth rate on embryonic breast muscle development in turkeys. Poult. Sci. 81:1113-1121. 